\begin{tabular}{|c|c|c|c|c|}
\hline JURNAL & \multirow{2}{*}{ VOLUME 2} & \multirow{2}{*}{ NOMOR 1 } & HALAMAN 1-73 & $\begin{array}{l}\text { ISSN 2655-8823 }(p) \\
\text { ISSN 2656-1786 }(e)\end{array}$ \\
\hline
\end{tabular}

\title{
RESOLUSI KONFLIK BERBASIS BUDAYA OLEH MASYARAKAT KABUPATEN POSO
}

\author{
Nanang Wijaya \\ Mahasiswa Program Doktoral Pascasarjana Kesejahteraan Sosial FISIP Unpad \\ E-mail: nanang.wijaya@gmail.com
}

\begin{abstract}
ABSTRAK
Konflik Poso pecah menjadi salah satu konflik terlama di Indonesia yang menyebabkan kerugian dan korban yang banyak. Segala upaya dilakukan untuk menanggulangi konflik dengan segala upaya resolusi konflik yang dilaksanakan. Selain upaya pemerintah dan aparat keamanan untuk menanggulangi konflik, masyarakat Poso melaksanakan upaya resolusi berbasis budaya. Kehadiran significant others (orang berpengaruh) melaksanakan proses resolusi konflik dengan menggunakan komunitas rumah kata sebagai lembaga melaksanakan resolusi konflik dengan menggunakan kearifan lokal Sintuvu Maroso dan kearifan lokal Tonda Talusi diterima oleh masyarakat yang bertikai.
\end{abstract}

Kata kunci: Konflik, Resolusi Konflik, kearifan lokal, Budaya

\section{PENDAHULUAN}

Pasca jatuhnya penguasa rezim orde baru Presiden Suharto, beberapa daerah di Indonesia mengalami konflik. Konflik paling besar yaitu Kalimantan Barat, Poso, Ambon, dan Maluku Utara. Ada berbagai macam pendapat tentang penyebab konflik-konflik tersebut seperti ketidakpastian transisi nasional, persaingan antar agama, persaingan ekonomi antar pendatang dan masyarakat lokal serta persaingan politik lokal (Acciaioli: 2001; Aditjondro: 2002; Aragon: 2001; Aspinall: 2008; Barron: 2008; Bertrand: 2004; Crouch: 2010; Davidson: 2009; Tornquist: 2000; Wessel and Wimhofer: 2001; Sidel: 2006; Baron, Kaiser and Pradhan: 2004; Varshney; Aspinall \& Felat, G: 2003; Malley \& Michael. S.: 2009).

Pada keempat daerah yaitu Ambon, Maluku Utara, Poso, dan Kalimantan Barat disebut sebagai konflik komunal karena memakan waktu yang lama dan korban yang banyak. Konflik Poso selama sembilan tahun terjadi sejak 1998 hingga 2007, akan tetapi sejak tahun 2003 konflik komunal berubah menjadi aksi-aksi kekerasan oleh kelompok-kelompok radikal yang terjadi sampai saat penelitian dilaksanakan. Khusus daerah Poso,
Ambon dan Maluku Utara konflik komunal berubah menjadi gerakan radikal keagamaan dengan aksi-aksi kekerasan yang dikategorikan sebagai gerakan teroris oleh pemerintah RI (Sidel: 2006; Aragon: 2007; Aspinall, Edward: 2008; Sirozi, M.: 2005; Hasan, N.: 2002; Harb \& Fischer: 2013; Kolig: 2005; Taylor: 2012; Bruinessen: 2002; Klinken: 2007; McRae: 2016; Ross, M. H.: 2009).

Sejak konflik pecah upaya perdamaian sudah dilaksanakan baik oleh Pemda Poso, Pemprov Sulawesi Tengah, Pemerintah Pusat, aparat keamanan dan Masyarakat Poso seperti yang telah dilaksananakan pada tanggal 22 Agustus 2000 penandatanganan Rujuk Sintuvu Maroso, akan tetapi konflik pecah lagi. Upaya damai kedua membuahkan hasil Deklarasi Malino pada tanggal 19 - 20 Desember 2001 dan membentuk Pokja Malino. Akan tetapi pasca penandatanganan perjanjian Malino aksi-aksi kekerasa di Poso terus terjadi. Komunitas Muslim ada yang merasa tidak terwakili dalam kesepakatan Deklarasi Malino (McRae: 2016; Komnas HAM; 2005; Damanik: 2000; Gogali: 2009; Hasrullah: 2004; Karnavian: 2008; Lasahido: 2003, Sihbudi: 2005). Artikel ini mencoba menganalisi upaya perdamaian oleh masyarakat Poso psca 


\begin{tabular}{|c|c|c|c|c|}
\hline JURNAL & \multirow{2}{*}{ VOLUME 2 } & \multirow{2}{*}{ NOMOR 1 } & HALAMAN 1-73 & $\begin{array}{l}\text { ISSN 2655-8823 }(p) \\
\text { ISSN 2656-1786 }(e)\end{array}$ \\
\hline
\end{tabular}

penandatanganan deklarasi Malini yang tidak menghentikan aksi-aksi kekerasan dengan pertanyaan yang hendak dijawab "Bagaimana Resolusi Konflik Berbasis Budaya Oleh Masyarakat Poso?", disamping operasi oleh aparat keamanan dalam upaya penanggulangan konflik, selain operasi Densus 88, aparat keamanan juga melaksanakan operasi militer sejak konflik Poso pecah (1998). Sejak tahun 2000, sudah dilaksanakan operasi militer Sadar Maleo yang kemudian dilanjutkan dengan operasi Sintuvu Maroso sejak tahun 2001, Sintuvu Maroso II 2002, Sintuvu Maraoso III 2003, Sintuvu Maroso IV 2004. operasi Camar Maleo sebagai lanjutan operasi Sintuvu Maroso, operasi Tinombala sejak tahun 2015 sampai disaat penelitian. (Albanna: 2017; Karnavian: 2018; Igneus: 2014).

\section{METODE PENELITIAN}

Penelitian ini juga menggunakan pendekatan kualitatif menginterpretasikan dan menjelaskan satu fenomena secara holistik dengan menekankan pemaknaan dengan menggunakan pendekatan deskriptif dalam penyajian laporan tentang upaya resolusi konflik Poso. Sumber data dalam pendekatan kualitatif adalah semua pihak yang berkepentingan. Fakta yang dibutuhkan meliputi kata-kata dan tindakan-tindakan informan yang memberikan data dan informasi dari informan kunci melalui suatu proses wawancara dan pengamatan. Pengumpulan data dilakukan melalui pengamatan/partisipasi aktif, studi dokumentasi dan wawancara. Sedangkan, jenis data yang dikumpulkan berupa data primer dan data sekunder. Sumber data dalam penelitian ini yaitu: Masyarakat Muslim Poso yang kami bagi kedalam 5 kategori yakni; a) ustaz-ustaz yang bermukin di Poso sejak tahun 1998 sampai sekarang; b) tokoh politik Muslim Poso yang telah bermukim di Poso sejak 1998 sampai sekarang; c) Mantan napi terorisme yang menjalani proses deradikalisasi di Poso. Masyarakat; d) Unsur pemerintah
Poso dari kabupaten hingga desa di Poso, serta dokumen, arsip dan data dari BNPT, FKPT, Kepolisian, TNI dan Pemda Poso berkaitan dengan penanggulangan konflik di Poso;

\section{HASIL DAN PEMBAHASAN}

Tokoh yang menjadi motor pelaksanaan upaya resolusi konflik berbasis budaya di Poso adalah Arifudin Lako yang biasa dipanggil Iin Bruru seorang mantan napiter dengan penahanan selama 8,6 tahun. Setelah menjalani masa penahanannya, Arifudin Lako langsung mengkoordinir kawan-kawan yang menjadi bawahannya semasa aktif di kelompok radikal dan membentuk komunitas Rumah Katu pada bulan November 2015 yang beranggotakan mantan napi terorisme yang mau bergerakn dalam bidang sosial budaya dalam mengupayakan resolusi konflik, perdamaian dan deradikalisasi.

Kegiatan Komunitas Rumah Katu yaitu : 1) temu Budaya antara dua komunitas Muslim dan Nasrani; 2) festival Budaya antara dua komunitas Muslim dan Nasrani; 3) pembuatan Film Pendek yang memuat pesan perdamaian, resolui konflik dan deradikalisasi; 4) pembinaan generasi muda (SMP dan SMU) dalam menciptakan keharmonisa antara dua komunitas Muslim dan Nasrani.

Komunitas Rumah Katu menjadi menjadi tebusan atas apa yang mereka telah lakukan membuat Poso dan masyarakat Poso terjebak dalam konflik berkepanjangan. Dalam Komunitas Rumah Katu terkumpul 50an orang mantan kombatan Muslim Poso dan mantan napi terorisme yang dikumpulkan oleh Arifuddin Loko. Arifuddin Loko merupakan salah seorang pemimpin massa yang paling berani dan dikenal pada masa konflik. Itu sebabnya Arifudin Loko sangat dihormati dan dikagumi oleh Masyarakat Muslim Poso.

Pada saat konflik Arifuddin Lako tergabung kedalam kelompok yang dibina dan mendapat pelatihan oleh jamaah 


\begin{tabular}{|c|c|c|c|c|}
\hline JURNAL & \multirow{2}{*}{ VOLUME 2 } & \multirow{2}{*}{ NOMOR 1 } & HALAMAN 1-73 & $\begin{array}{l}\text { ISSN 2655-8823 }(p) \\
\text { ISSN 2656-1786 }(e)\end{array}$ \\
\hline
\end{tabular}

Islamiyyah bahkan menjadi salah seorang tim 10, tim yang mendapat tugas melakukan pembunuhan di beberapa tempat di Poso dan Kota Palu. Komunitas Rumah Katu memilih untuk tidak mengungkit-ungkit permasalahan konflik yang pernah terjadi sebab akan kembali membangkitkan trauma masyarakat Poso. Komunitas Rumah Katu memilih untuk mengkaji bagaimana masa depan Poso yang harus dibangun. Ini merupakan bentuk objektivasi kehendak damai dan aman dari mereka yang tergabung dalam Komunitas Rumah Katu.

Komunitas Rumah Katu mensosialisasikan kearifan lokal pada masyarakat Muslim Poso dengan menggunakan kearifan "Sintuvu Maroso" dan kearifan "Tonda Talusi" terus dikembangkan dan diobjektivasi oleh Komunitas Rumah Katu dalam sejumlah kegiatannya. Sintuvu Maroso adalah kearifan masyarakat Poso yang sudah ada sejak masa lalu yang kemudian terabaikan dan terlupakan. Sintuvu Maroso sebelum konflik komunal Poso pecah dengan Sintuvu Maroso setelah konflik komunal Poso pecah dimaknai dan diobjektivasi masyarakat Poso berbeda.

Sintuwu Maroso dalam bahasa Poso mengandung dua makna yaitu Sintuwu yang berarti bersatu atau persatuan sedangkan maroso berarti kuat sehingga apabila digabungkan berarti persatuan yang kuat. Konflik yang berkepanjangan menyebabkan kearifan lokal Sintuvu Maroso memiliki pemaknaan yang lebih kuat. Sintuvu Maroso bermakna persaudaraa, solidaritas, kebersamaan dengan tiga dimensi, yakni: hidup saling menghargai (tuwu mombetuwunaka), hidup saling menghidupi (tuwu mombepatuwu), dan hidup saling menolong (tuwu mombesungko).

Perilaku yang lahir dari internalisasi nilai Sintuvu Maroso sejalan dengan nilai Islam rahmatan lil alamin, keanekaragaman etnis dan agama menjadi terjembatani dalam proses interaksi dalam masyarakat. Saling menghargai dan saling menghormati menjadi perilaku yang terobjektifikasi dalam proses konstruksi sosial masyarakat Muslim Poso dan masyarakat agama lain. Menempatkan tokoh masyarakat Muslim dengan tokoh masyarakat agama lain pada posisi di pemerintah dan keterlibatan dalam proses deradikalisasi menjadi objektivasi saling menghargai.

Pada awalnya pendekatan budaya selalu mendapat penolakkan dari kelompok radikal Muslim Poso sebab dianggap bertentangan dengan ajaran Islam, akan tetapi pemaknaan Sintuvu Maroso pasca konflik menjadi sangat sesuai dengan ajaran Islam dalam upaya mewujudkan perdamaian. Sebagaimana diungkapkah oleh Arifudin Lako (41 tahun):

"Kita punya Sintuvu Maroso yang tidak pilah-pilah masyarakat, pokoknya semua sama selama dia masyarakat Poso, hidup di Poso, walaupun kita punya agama yang berbeda tapi Sintuvu Maroso melarang untuk saling mengganggu. Islam dengan budaya itu saling mendukung, menguatkan, tidak saling bertentangan, karena konfliknya di Poso dari Islam dan Kristen, kita cari yang bisa mempersatukan keduanya.

Dengan karakter saling menyatukan dua agama yang berbeda dengan prinsip tidak saling mengganggu tapi bekerja sama demi Poso. Hal ini yang menyebabkan pilihan atas kearifan Sintuvu Maroso yang digunakan oleh Komunitas Rumah Katu untuk resolusi konflik dan penciptaan perdamaian. Hal yang sama juga dikedepankan dalam upaya pembinaan para mantan combatan maupun pelaku aksi kekerasan.

Penghindaran atas konflik dan pelepasan diri dari segala bentuk idiologi yang mengajarkan kekerasan berangkat dari makna inti dari Sintuvu Maroso. Seluruh masyarakat Poso, baik lokal maupun pendatang bersepakat dalam interaksi dibangun berbasis Sintuvu Maroso. Deradikalisasi terlegitimasi oleh 


\begin{tabular}{|c|c|c|c|c|}
\hline JURNAL & \multirow{2}{*}{ VOLUME 2 } & \multirow{2}{*}{ NOMOR 1 } & HALAMAN 1-73 & $\begin{array}{l}\text { ISSN 2655-8823 }(p) \\
\text { ISSN 2656-1786 }(e)\end{array}$ \\
\hline
\end{tabular}

kearifan Sintuvu Maroso. Sementara dalam pengelolaan politik pemerintahan masyarakat Poso terlegitimasi oleh Tonda Talusi yakni pemerintahan dikelolah oleh tiga unsur yakni Pemerintah, Aparat Kemanan dan Tokoh.

Pengambilan-pengambilan keputusan dan kebijakan berdasarkan musywarau tiga unsur di dalam masyarakat. Termasuk penyelesaian masalah-masalah di masyarakat, sebelum masuk ke ranah hukum formal elemen Tonda Talusi terlebih dahulu mengupayakan penyelesaiannya. Tiga elemen dalam Tonda Talusi yaitu: 1) mereka yang dituakan sehingga diakui kearifannya; 2) mereka dihormati sehingga didengarkan keputusannya,, ; dan 3) mereka yang dimuliakan sehingga diikuti titah atau perintahnya. Deradikalisasi mendapat legitimasi dari Tonda Talusi dalam pencapaian perdamaian dan keamanan. Kebijakan-kebijakan yang dikeluarkan menjadi bagian dalam pengupayaan pencegahan radikalisme dan terorisme. Deradikalisasi mendapat peneguhan dan penguatan dari Tonda Talusi melalui kebijakan, kearifan dan keputusan.

Legitimasi berbasis kearifan lokal menciptakan: 1) pengakuan keragaman budaya yang dapat dijadikan basis dalam pengelolaan perdamaian di Poso; 2) pengakuan persamaan hak dan martabat antar komunitas etnis; 3) tanggungjawab bersama terlepas dari beragam etnis dalam menjaga perdamaian dan keamanan; 4) ikatan solidaritas yang kuat dalam masyarakat; dan 5) membangun cita-cita bersama dalam upaya kedamaian dan kebahagiaan.

Dalam upaya penanggulangan konflik sampai pada proses rekonsiliasi pasca konflik komunal di Poso, signficant others (orang berpengaruh) senantiasa hadir menjadi kenyataan yang mempengaruhi dalam proses penciptaan keamanan, perdamaian dan resolusi konflik. Significant others berupa tokoh masyarakat, tokoh agama dan tokoh pemuda yang terus berupaya melaksanakan resolui konflik, mengusahakan terwujudnya perdamaian dan berjalannya proses deradikalisasi pada masyarakat Muslim Poso.

Ketika konflik pecah, signicant others muncul dari pemimpin-pemimpin lembaga adat pada masyarakat Poso sebanyak 13 orang yang mewakili 10 sub etnis Pamona ditambah etnis Jawa, etnis Bugis dan etnis Kaili berkumpul mencari cara agar konflik dapat dihentikan dan tidak melebar. Kesepakatan 13 pimpinan lembaga adat menyepakati perdamaian dengan melakukan upacara rekonsiliasi berbasis adat yang diberi nama "Rujuk Sintuvu Maroso”. Akan tetapi Rujuk Sintuvu Maroso gagal dengan terbukti konflik pecah kembali dan menyebar hampir diseluruh Poso. Kegagalan Rujuk Sintuvu Maroso karena sebagian umat Islam yang mulai terpengaruh dengan doktrin radikalisme lebih memilih untuk membalas dendam. Dengan dalih upacara adat oleh 13 pimpinan lembaga adat tidak sesuai dengan syariat Islam, kelompok Muslim mulai melancarkan balas dendam dengan melakukan aksi-aksi kekerasan yang oleh aparat keamanan dikategorikan tindakan terorisme atau konflik Poso.

Tokoh yang menjadi significant others yang sangat berpengaruh besar dalam pencapaian perdamaian dan keberhasilan deradikalisasi yaitu Arifudin Loko alis Brus alias Iin seorang mantan napi terorisme setelah mendapatkan kesadaran berhasil mengumpulkan sesama pelaku aksi-aksi kekerasan dan melakukan pembinaan, kegiatan Arifudin Loko alias Brur alias Iin terobjektivasi kedalam Komunitas Rumah Katu. Significant other berperan sebagai penjaga nilai dengan cara mensosialisasikannya kepada generasigenerasi berikutnya maupun yang sekarang.

\section{KESIMPULAN}

Upaya resolusi konflik sangat membutuhkan tokoh yang sangat dihormati oleh masyarakat yang terus mensosialisasi nilai-nilai yang digunakan 


\begin{tabular}{|c|c|c|c|c|}
\hline JURNAL & \multirow{2}{*}{ VOLUME 2 } & \multirow{2}{*}{ NOMOR 1 } & HALAMAN 1-73 & $\begin{array}{l}\text { ISSN 2655-8823 }(p) \\
\text { ISSN 2656-1786 }(e)\end{array}$ \\
\hline
\end{tabular}

mencapai upaya resolusi konflik. Tokoh masyarakat atau yang disebut sebagai signficant others menentukan nilai apa yang akan digunakan dalam upaya resolusi konflik diterima oleh masyarakat. Nilai budaya menjadi pilihan yang tepat untuk digunakan sebagai legitimasi resolusi konflik. Nilai diterima oleh pihak-pihak yang konflik dan dilaksanakan secara bersama-sama sehingga terwujud keadaan aman dan perdamaian.

Nilai budaya diterima oleh kedua pihak bertikai karena dianggap tidak menyinggung atau tidak berkesesuaian satu kelompok yang bertikai. Nilai agama akan kesulitan dipakai sebagai nilai dalam resolusi konflik pada konflik yang berdasarkan agama. Penggunaan nilai agama akan ditolak oleh kelompok yang berbeda agama. Maka penggunaan nilai budaya selama tidak bertentangan dengan agama apapun akan diterima sebagai nilai resolusi konflik.

\section{DAFTAR PUSTAKA}

Acciaioli, G. (2001). Grounds of Conflict, Idioms of Harmony: Custom, Religion, and Nationalism in Violence Avoidance at the Lindu Plain, Central Sulawesi. Indonesia, 72, 81. doi: $10.2307 / 3351482$

Aditjondro 2004 Kerusahan Poso dan Morowali ; akar permasalahan dan jalan keluarnya, makalah seminar "penerapan keadaan darurat di Aceh, Papua dan Poso, ProPatria, Jakarta .

Albanna, Dien. 2017. Operasi Tinombala: Perburuan Gembong Teroris Santoso. Jember. Jember Katamedia.

Aragon, L. V. 2001. Communal Violence in Poso, Central Sulawesi: Where People Eat Fish and Fish Eat People. Indonesia, $72, \quad 45$. doi: $10.2307 / 3351481$

Aspinall and Felat, G. 2003. Local Power and politics in indonesia; decentralisation and democratisation, Singapore: ISEAS

Baron, Kaiser dan Pradhan 2004 Local conflict in indonesia; Measuring incidience and indentifying patters, Jakarta: World Bank Online

Bertrand, Jacques. 2004. National and ethnic conflict in Indonesia. Cambridge: Cambridge University Press.

Bruinessen, Van Martin. (2002). Genealogies of Islamic Radicalism in Post-Suharto Indonesia. South East Asia Research, 10(2), 117-154. doi:10.5367/000000002101297035

Crouch, Harold. 2010. Political reform in Indonesia after Suharto. Singapore. ISEAS Publishing

Damanik, Rinaldy. 2000. Tragedi Kemanusiaan Poso; Menggapai Surya Pagi Melalui Kegelapan Malam. Sulawesi Tengah. PBHI\& LPS-HAM.

Davidson, S. J. (2009). Studies of Massive, Collective Violence in PostSoeharto Indonesia. Critical Asian Studies, 41(2), 329-349. doi:10.1080/14672710902809450

Harb, C., \& Fischer, R. (2013). Terrorism and jihad in Indonesia: Questions and possible ways forward. Asian Journal of Social Psychology, 16(2), 117-122. doi:10.1111/ajsp. 12020

Hasan, Noorhaidi. 2008. Laskar Jihad ; Islam, Militansi dan Pencarian Identitas di Indonesia Pasca Orde Baru. Jakarta. LP3ES.

Hasan, N. (2002). Faith and Politics: The Rise of the Laskar Jihad in the Era of Transition in Indonesia. Indonesia, 73, 145. doi:10.2307/3351472

Hasrullah, 2004. Dendam Konflik Poso; Periode 1998-2001. Jakarta. Gramedia.

Igneus, Alganih. 2014. Konflik Poso (Kajian Historis Tahun 1998-2001). S1 thesis, Universitas Pendidikan Indonesia.

Karnavian, Tito. 2008. Top Secret; Membongkar Konflik Poso. Jakakrta. Gramedia

Klinken, Gerry Van. 2007. Perang Kota Kota Kecil. Jakarta. Yayasan Obor Indonesia.

Kolig, E. (2005). Radical Islam, Islamic Fervour, and Political Sentiments in 


\begin{tabular}{|c|c|c|c|c|}
\hline JURNAL & \multirow{2}{*}{ VOLUME 2} & \multirow{2}{*}{ NOMOR 1 } & HALAMAN 1-73 & $\begin{array}{l}\text { ISSN 2655-8823 }(p) \\
\text { ISSN 2656-1786 }(e)\end{array}$ \\
\hline
\end{tabular}

Central Java, Indonesia. European Journal of East Asian Studies, 4(1), 55-86. doi:10.1163/1570061054030341

KomnasHam. 2005. Poso; Kekerasan Yang Tak Kunjung Usai. Jakarta. Komnas Ham.

Komnas HAM. 2005. Interaksi Antara Moyoritas dan Minoritas Agama. Jakarta : Departemen Hukum dan Hak Asasi Manusia Republik Indonesia Lasahido, Tahmidy dkk.2003. Suara Dari Poso ; Kerusuhan, Konflik dab Resolusi. Jakarta. Alinasi Masyarakat Sipil Untuk Demokrasi (YAPPIKA).

Malley, Michael. S. 2009.. Regions, centralization and resistence, dalam Donald K. Emerson (ed) Indonesia Beyond Suharto; Polity, economy, Society, transition. New York; M.E Sharpe

McRae, Dave. 2016. Poso; Sejarah Komprehensif Kekerasan Antar Agama Terpanjang di Indonesia Pasca Reformasi. Jakarta. Marjin Kiri.

Ross, M. H. 2009. Riots, Pogroms, Jihad: Religious Violence in Indonesia. By John T. Sidel. Ithaca and London: Cornell University Press. 304p. $\$ 57.95$ cloth, \$21.00 paper. Perspectives on Politics, 7(01), 161-163. doi:10.1017/s1537592709090239

Sihbudi, 2005. Konflik Poso; Pemetaan dan Pencarian Pola-Pola Alternatif Penyelesaian. Jakarta. Pusat Penelitian Politik Lembaga Pengetahuan Indonesia (P2P-LIPI).

Sidel, John T. 2006. Riots, Progroms, Jihad; Religious Violence in Indonesia. Cornel University Press.

Sirozi, M. (2005). The Intellectual Roots of Islamic Radicalism in Indonesia: Ja'far Umar Thalib of Laskar Jihad (Jihad Fighters) and His Educational Background*. The Muslim World, 95(1), 81-120. doi:10.1111/j.14781913.2005.00080.x

Taylor, J. G. (2012). The End of Innocence? Indonesian Islam and the Temptations of Radicalism. Asian
Affairs, $\quad 43(2), \quad 334-337$.

doi:10.1080/03068374.2012.682761

Tornquist 2000 Politics violence; Indonesia and india in comparative perpective. Oslo; Centre for Development and the Environmrent (SUM)

Varshney, Panggabean dan Tadjoeddin 2003, Patterns of collective violence in indonesia (1999-2003), Jakarta UNSFIR

Wessel dan Wimhofer 2001 Violence in Indonesia, Hamburg; Abera-Verl 